\title{
EDITORIAL
}

\section{MUSEO ARQUEOLÓGICO SAN MIGUEL DE AZAPA: 50 A ÑOS DE INVESTIGACIÓN, PROTECCIÓN Y DIFUSIÓN DEL PATRIMONIO CULTURAL DE LA REGIÓN DE ARICA Y PARINACOTA}

\author{
Iván Muñoz O. ${ }^{1}$ y Vivien G. Standen
}

\begin{abstract}
El Museo Arqueológico San Miguel de Azapa (MASMA) dependiente de la Universidad de Tarapacá (UTA) viene desarrollando por cinco décadas, una actividad museológica ininterrumpida: estudiando, protegiendo, difundiendo y poniendo el valor el patrimonio cultural de la región. Dicha labor, que surge junto al desarrollo de la universidad en la ciudad de Arica, ha permitido que esta institución se establezca como un referente museístico a nivel nacional e internacional. Tal ha sido su importancia para nuestra universidad, que junto con considerar a la disciplina antropológica un área prioritaria en los planes estratégicos de los últimos 15 años, actualmente representa un pilar fundamental en los procesos de acreditación académica en relación a su vinculación con el medio.
\end{abstract}

El MASMA, que en noviembre del año 2017 celebró 50 años de existencia, desde su fecha de creación, ha sido un protagonista directo del desarrollo de la investigación y extensión académica en la disciplina antropológica universitaria. Este rol protagónico ha permitido la formación de equipos de investigadores, encuentros internacionales de antropología y arqueología, edición y publicación de revistas y libros, que dan cuenta de los distintos procesos culturales que han acaecido en la región desde los últimos 10.000 años. Sobre este museo, además, recayó la responsabilidad de la creación del Departamento de Antropología, el año 1972, que se constituyó luego, en el Instituto de Antropología, unidad académica que permitió su proyección internacional, con exposiciones más periódicas en las dependencias del propio museo y la itinerancia de exposiciones de su colección, en el ámbito nacional e internacional.
Posteriormente, en la década de los años ochenta, se comienzan a impulsar ciertas actividades de difusión del patrimonio, a través de algunas publicaciones que, de cierta manera, ayudaron a crear conciencia de la importancia del patrimonio arqueológico regional y la necesidad de difundirlo. Se creó por ejemplo el circuito arqueológico del valle de Azapa, cuya función complementaria al museo, mostraba a través de una red de asentamientos y cultura material, la vida y costumbres de las sociedades prehispánicas, posthispánicas y afrodescendientes que han habitado el territorio.

Por su parte, la investigación generada al alero del Museo Arqueológico San Miguel de Azapa, ha profundizado en una serie de temas relacionados con los primeros poblamientos y la adaptación de la vida humana al desierto, el más árido del planeta. En particular en el caso de las sociedades de caza, pesca y recolección, los estudios de la Cultura Chinchorro, han apuntado a conocer características del medio ambiente, tecnologías y los patrones de movilidad; así como el origen y desarrollo de las practicas funerarias. Lograron desarrollar la momificación artificial, la más antigua del mundo, transformando los cuerpos inertes en efigies funerarias modeladas en arcilla y/o rellenas con fibra vegetal, pieles de camélidos y plumajes de aves marina.

En el caso de las sociedades aldeanas, es decir, cuando las poblaciones desarrollan nuevas estrategias adaptativas para vivir en el desierto, como fue la domesticación de plantas y animales, los estudios han sido más diversos por la complejidad del tema. Cabe mencionar los patrones de ocupación de los valles costeros y serranos, el manejo tecnológico

Departamento de Antropología, Universidad de Tarapacá, Arica, Chile.imunoz@uta.cl; vstanden@chungara.cl 
de los recursos hídricos, la importancia de los cerros en el contexto ceremonial, las características y comportamiento tecnológico, especialmente en la definición de estilos, formas y técnicas para la manufactura de la cerámica y la textilería.

Desde la perspectiva bioantropológica, y gracias a las excelentes condiciones de preservación que presentan los cuerpos humanos, se han abierto novedosas líneas de investigación como los estudios de la paleodieta, salud y enfermedad, crecimiento y desarrollo, violencia, y los estudios sobre contaminantes a los que estuvieran expuestas estas tempranas poblaciones que habitaron la actual región de Arica y Parinacota.

Evidentemente, en esta extensa labor académica, ha habido una estrecha relación entre la investigación y la museología, lo que ha permitido ejecutar proyectos, puesta en valor y difusión del patrimonio local, como, por ejemplo, la preservación y restauración del Pukara de San Lorenzo en el valle de Azapa; el Pukara de Copaquilla y el Tambo de Zapahuira, en la precordillera de Arica; los geoglifos de los valles costeros y salares del extremo norte de Chile; y recientemente el Museo de sitio Colón-10, en el centro de la ciudad de Arica. Por otro lado, la construcción de laboratorios y depósitos, donde se ha generado la investigación y conservado las colecciones arqueológicas, constituyen el eje sobre el que se estructura el MASMA, cuya misión es estudiar, conservar, proteger y difundir el patrimonio arqueológico, histórico y etnográfico que mantiene en su colección, conformada por más de 90.000 piezas.

De la misma manera que el museo se ha enlazado con la investigación, a nivel de la docencia universitaria, participa en la formación de estudiantes de pre y postgrado de la disciplina antropológica, facilitando como material de estudio, las colecciones que se hayan registradas y conservadas. Por otro lado, hay apoyo en la dictación de cursos de museología y conservación del patrimonio cultural a los estudiantes de arqueología. En los últimos 10 años, esta cooperación se ha ampliado a los estudiantes de la UTA en general, fundamentalmente, con el apoyo a memorias y tesis de grado, y en la creación de software en que se relevan procesos históricos y precolombinos.

Después de 50 años de existencia, el MASMA se ha constituido en un actor cultural fundamental en la región, y con la perspectiva cierta que con la construcción de un gran edificio con nuevas dependencias, que incluye salas de exposición y depósitos, el museo constituirá un faro cultural de amplia proyección en el centro oeste de Sudamérica. De tal manera que, con una museografía moderna, el visitante podrá aprender la forma en que las sociedades humanas se ha adaptado a uno de los desiertos más áridos del mundo. Insertándose, además, en un circuito de turismo cultural andino de relevancia mundial, integrado por Tiwanaku y Machu Picchu, lugares que muestran la adaptación de las tempranas poblaciones a ambientes de alturas y a climas desérticos y tropicales.

\section{El nuevo museo y su proyección}

El posicionamiento que ha adquirido el museo en la región, es evidente, al considerárselo un garante de la preservación y promoción del patrimonio regional. El reconocimiento que ha adquirido en sus esfuerzos por fortalecer los vínculos con la comunidad, inserta en una región bifronteriza, desértica, costera y andina, ha estimulado el interés de las autoridades regionales de apoyar un proyecto museo inserto en el plan de zonas extremas (PEZDE), con estándares internacionales en cuanto a infraestructura. Esperamos que con su construcción se fortalezcan más aún las relaciones con la comunidad, que nos permita a través del patrimonio cultural y natural, establecer una configuración enmarcada en una identidad regional. En ese sentido, como una forma de tener una mejor respuesta a las políticas públicas que postulan a los museos como un agente principal de cultura, en una relación dialógica de apropiación comunitaria.

En cuanto a la Vinculación y Educación de Museo, se estructurará una Gobernanza público-privada para el Desarrollo del Circuito Cultural y Natural del valle de Azapa, facilitando la capacitación de los agentes culturales de la región con interés en la interpretación del patrimonio del valle. Por otro lado se realizarán capacitaciones y cursos a profesionales interesados en materias como museografía, conservación del patrimonio cultural, así como charlas de empoderamiento patrimonial a la comunidad y escuelas de la región.

En relación a la museografía del actual museo se realizó la remodelación de la sala de exhibición, generando una nueva concepción de vitrinas, tipo galerías, permitiendo un mayor acercamiento del visitante a las piezas exhibidas. Esta remodelación, permitirá mantener una actualización museográfica, durante este proceso de transición, hasta que se construya el nuevo museo.

Finalmente en materia de investigación la información que arroje el registro de colecciones, sumada al ingreso de nuevos materiales, permitirá que se sigan trabajando nuevos temas, enriqueciendo la problemática del pasado precolombino, desarrollándose paralelamente nuevas líneas de investigación en el ámbito de la etnohistoria y la antropología. 